\title{
OPEN Pulmonary adiaspiromycosis in armadillos killed by motor vehicle collisions in Brazil
}

\begin{abstract}
Pedro Enrique Navas-Suárez ${ }^{1 凶}$, Carlos Sacristán ${ }^{1}$, Josue Díaz-Delgado ${ }^{1,2}$, Débora R. Yogui ${ }^{3,4}$, Mario Henrique Alves ${ }^{3,5}$, Danny Fuentes-Castillo ${ }^{1}$, Catalina Ospina-Pinto ${ }^{1}$, Roberta Ramblas Zamana ${ }^{1}$, Arnaud Leonard Jean Desbiez ${ }^{3,6}$ \& Jose Luiz Catão-Dias ${ }^{1}$

Knowledge of infectious diseases in wildlife provides important information for preventing potential outbreaks of zoonotic diseases. Adiaspiromycosis is a neglected human disease caused by dimorphic Onygenales fungi. The disease is produced by the inflammatory response against growing adiaspores, leading to granulomatous pneumonia. In humans, adiaspiromycosis is relevant in immunosuppressed patients. In animals, it is associated with pneumonia in fossorial species. Given the potential role of armadillos in the epidemiology of adiaspiromycosis, in this study, we sought to investigate the occurrence and pathological features of adiaspiromycosis in roadkilled armadillos. In total, 54 armadillo carcasses were suitable for postmortem pathologic examinations between February 2017 and 2020. Adiaspores, associated with granulomatous lesions, were observed in ten six-banded (Euphractus sexcinctus) and two southern naked-tailed armadillos (Cabassous unicinctus). A previously uncharacterized Onygenales species was molecularly identified in two $E$. sexcinctus. In summary, herein we report 12 cases of pulmonary adiaspiromycosis (PA) in two species of freeliving armadillos in Brazil. Both, the morphology of the fungus, as well as the histopathological findings (granulomatous inflammatory response to adiaspores) are consistent with PA; however, as the molecular identification differs from the reported species, the potential impact of this fungus for human PA is unknown, and we cannot rule out its impact on public health.
\end{abstract}

Surveillance of infectious diseases in wildlife is a valuable tool for the prevention and reduction of human disease outbreaks $^{1,2}$. Armadillos (order Cingulata) play a role in the epidemiological cycle of some zoonoses (e.g., hanseniasis and paracoccidioidomycosis) $)^{3,4}$. Despite being protected species, armadillo meat is commonly consumed in several South American countries ${ }^{5,6}$. Direct contact between humans and armadillos could pose a transmission route for several pathogens, thus, health investigations on armadillos may be relevant to public health.

Adiaspiromycosis is a fungal disease caused by the dimorphic fungi Emmonsia crescens and Blastomyces parvus (formerly known as Emmonsia parva) (family Ajellomycetaceae, order Onygenales), considered saprophytes and commonly isolated from the soil ${ }^{7}$. In contrast to other mycoses, once their conidia enter the host, mainly through respiratory via, they become adiaconidia (adiaspores), precluding their replication but increasing their size $^{8}$. The disease is caused by the host's immune response against the growing adiaspores, leading to the formation of granulomas 9 . The lesions are mainly restricted to the lungs and occasionally regional lymph nodes, although ocular and systemic adiaspiromycosis have also been described ${ }^{8,10}$. These lesions have been reported in humans, wild fossorial mammals (rodents, moles, armadillos), some species of carnivores, deer, horses and anurans (“Supplementary Material”).

The first description of the disease was made in wild rodents of the United States in the $1940 \mathrm{~s}^{11}$. In humans, the first case was reported in France in the $1960 \mathrm{~s}^{12}$. Adiaspiromycosis was widely studied in the 1970s, mainly in wild small mammals ${ }^{13}$. Nevertheless, reports have been intermittent during the last decades. While human cases are generally associated with immunosuppression, the clinico-pathological features in free-ranging animals remain largely unknown ${ }^{14-18}$. Human pulmonary adiaspiromycosis (PA) is generally an incidental finding in diagnostic images (X-rays and tomography) and can be a differential diagnosis of tuberculosis and/or

\footnotetext{
${ }^{1}$ Department of Pathology (VPT), School of Veterinary Medicine and Animal Science (FMVZ), University of São Paulo (USP), São Paulo, Brazil. '2Texas A\&M Veterinary Medical Diagnostic Laboratory, College Station, TX, USA. ${ }^{3}$ Instituto de Conservação de Animais Silvestres (ICAS), Campo Grande, Brazil. ${ }^{4}$ Nashville Zoo, Nashville, USA. ${ }^{5}$ Houston Zoo, Houston, USA. ${ }^{6}$ Royal Zoological Society of Scotland, Edinburgh, UK. ${ }^{\varpi}$ email: pedroenasu@ gmail.com
} 


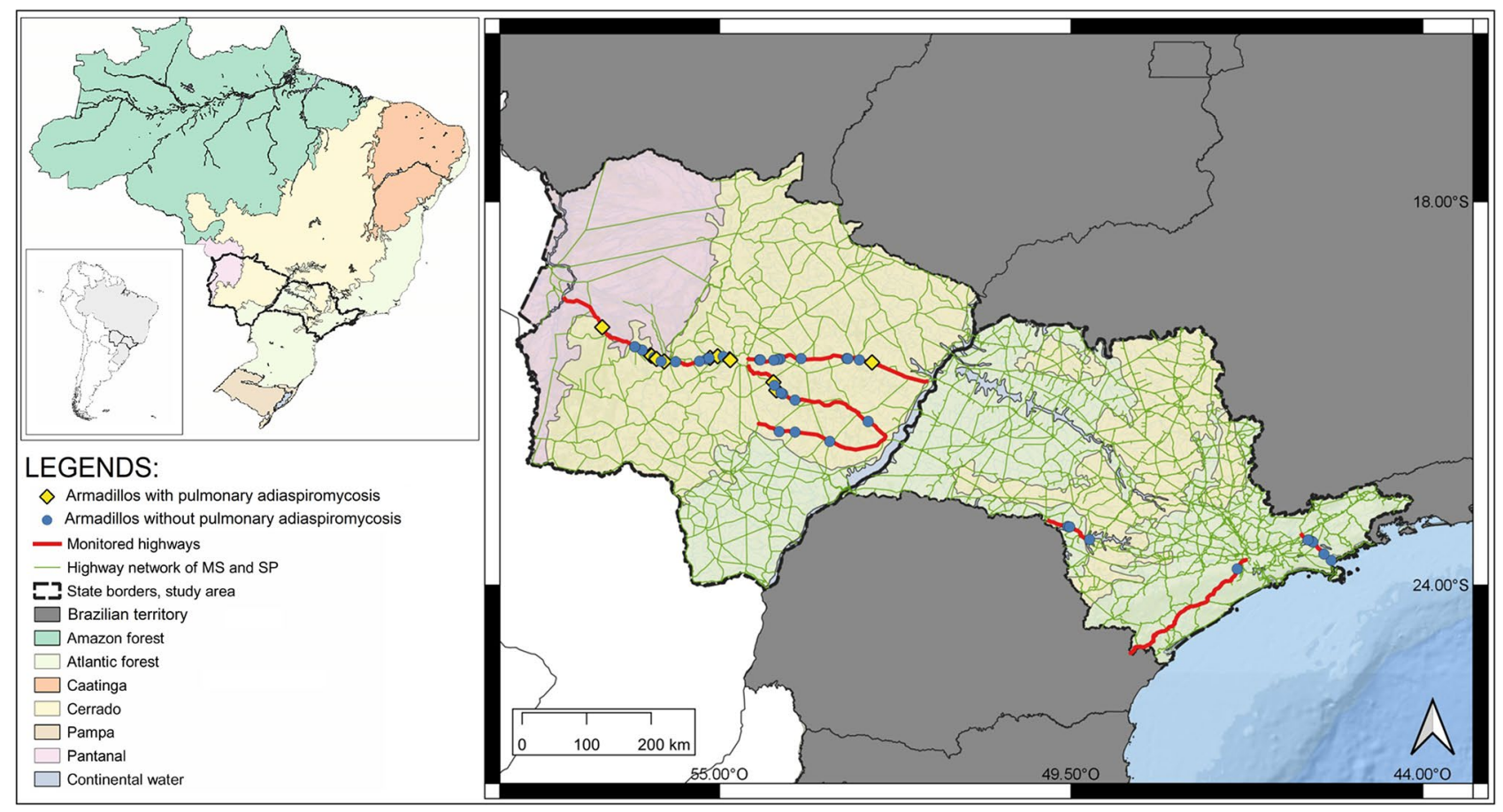

Figure 1. Geographic distribution of necropsied armadillos in roads of Mato Grosso do Sul and Sao Paulo states (Brazil) between February 2017 and February 2020. The map was created by software QGIS 3.16 (https:// qgis.org/).

pulmonary neoplasms; its definitive diagnosis is made by fungal culture and biopsy ${ }^{19-21}$. In Brazil, human cases have increased, and adiaspiromycosis is listed as a class II infectious agent (moderate individual risk and limited risk to the community) by the Ministry of $\mathrm{Health}^{22}$. In Brazilian animals, Emmonsia sp. was detected by PCR in one nine-banded armadillo (Dasypus novemcinctus) killed by motor-vehicle collision (MVC) in Botucatu, São Paulo State, however, no anatomopathological data were reported ${ }^{23}$. Adiaspiromycosis has been also described in three other armadillo species: hairy (Chaetophractus villosus), pichi (Zaedyus pichiy) and seven-banded armadillo (Dasypus septemcinctus) from Argentina ${ }^{24}$.

Since there are reports of PA in Brazil, and the etiologic agent has already been reported in armadillos (preliminarily by molecular technique ${ }^{23}$, we hypothesized a possible role of armadillos in the epidemiology of PA. Considering that the number of wild animals killed by MVC in Brazil is remarkable ${ }^{25}$, and the potential role of armadillos in the epidemiology of adiaspiromycosis, in this study, we sought to investigate the occurrence and pathological features of adiaspiromycosis in roadkilled armadillos. Here we report 12 cases of PA in two species of wild armadillos of Brazil: the six-banded armadillo (Euphractus sexcinctus) and the southern naked-tailed armadillo (Cabassous unicinctus).

\section{Results}

During the study period, 54 necropsies were performed in four armadillo species: nine-banded armadillo (Dasypus novemcinctus, 48.1\%; 26/54), six-banded (E. sexcinctus, 38.9\%;21/54), southern naked-tailed (C. unicinctus, 9.3\%; 5/54) and giant-armadillo (Priodontes maximus, 3.7\%; 2/54). Geographic distribution of all armadillos is shown in Fig. 1.

Ten E. sexcinctus $(47.6 \% ; 10 / 21)$ and two C. unicinctus $(40 \% ; 2 / 5)$ showed pulmonary histopathological findings with adiaspores morphologically most compatible with Emmonsia crescens or Blastomyces parvus. These cases were distributed in seven municipalities of MS, while no cases were found in SP. Complete biological and epidemiological data of armadillos with adiaspiromycosis are listed in Table 1 . The main pulmonary gross findings associated with motor vehicle collisions (MVC) were hemorrhage (100\%; 12/12), parenchymal rupture $(66.7 \% ; 8 / 12)$ and congestion $(50 \% ; 6 / 12)$ ("Supplementary Material”). Additionally, scattered $0.5-1 \mathrm{~mm}$ indiameter, slightly demarcated, pale tan to yellow nodules were observed throughout the parenchyma of all lung lobes $(25 \%$; 3/12), these nodules corresponded to PA (Fig. 2).

Microscopically, all these armadillos had pulmonary adiaspores with varying degrees of localized inflammation, ranging from none to marked granulomatous response (Table 2). Morphologically, adiaspores presented a bi- or trilaminar wall comprising a thin and brightly eosinophilic outer layer, a thick pale eosinophilic mid layer, and an internal basophilic layer which surrounded a core of round basophilic granular material but did not exhibit endospores. Adiaspores averaged $91.1 \mu \mathrm{m}$ in diameter (ranged from 10.9 to $839.5 \mu \mathrm{m}$ ) and were distributed multifocally within the alveolar and bronchial interstitium spaces. Adiaspores' wall components were highlighted by PAS, GMS and WS stains (Fig. 2). Inflammation severity correlated to adiaspores' size and varied from few reactive macrophages surrounding the adiaspores to severe nodular granulomatous inflammation with 


\begin{tabular}{|c|c|c|c|c|c|c|c|c|c|}
\hline Case & Common name & Species & Age-class & Sex & Year & Month & Season & Municipality & State \\
\hline 1 & SBA & $\begin{array}{l}\text { Euphractus } \\
\text { sexcinctus }\end{array}$ & Adult & Undetermined & 2017 & November & Rain & Miranda & MS \\
\hline 2 & SBA & $\begin{array}{l}\begin{array}{l}\text { Euphractus } \\
\text { sexcinctus }\end{array} \\
\end{array}$ & Adult & Female & 2017 & March & Rain & Terenos & MS \\
\hline 3 & SBA & $\begin{array}{l}\text { Euphractus } \\
\text { sexcinctus }\end{array}$ & Adult & Female & 2017 & June & Dry & Terenos & MS \\
\hline 4 & SNTA & $\begin{array}{l}\text { Cabassous } \\
\text { unicinctus }\end{array}$ & Adult & Male & 2017 & October & Rain & Água Clara & MS \\
\hline 5 & SBA & $\begin{array}{l}\begin{array}{l}\text { Euphractus } \\
\text { sexcinctus }\end{array} \\
\end{array}$ & Adult & Male & 2017 & November & Rain & Terenos & MS \\
\hline 6 & SNTA & $\begin{array}{l}\text { Cabassous } \\
\text { unicinctus }\end{array}$ & Juvenile & Male & 2017 & December & Rain & Campo Grande & MS \\
\hline 7 & SBA & $\begin{array}{l}\text { Euphractus } \\
\text { sexcinctus }\end{array}$ & Adult & Female & 2017 & December & Rain & Aquidauana & MS \\
\hline 8 & SBA & $\begin{array}{l}\text { Euphractus } \\
\text { sexcinctus }\end{array}$ & Adult & Male & 2018 & January & Rain & Aquidauana & MS \\
\hline 9 & SBA & $\begin{array}{l}\text { Euphractus } \\
\text { sexcinctus }\end{array}$ & Adult & Male & 2018 & February & Rain & Anastácio & MS \\
\hline 10 & SBA & $\begin{array}{l}\text { Euphractus } \\
\text { sexcinctus }\end{array}$ & Adult & Female & 2018 & June & Dry & Anastácio & MS \\
\hline 11 & SBA & $\begin{array}{l}\text { Euphractus } \\
\text { sexcinctus }\end{array}$ & Adult & Male & 2018 & July & Dry & Terenos & MS \\
\hline 12 & SBA & $\begin{array}{l}\text { Euphractus } \\
\text { sexcinctus }\end{array}$ & Adult & Male & 2018 & July & Dry & $\begin{array}{l}\text { Ribas do Rio } \\
\text { Pardo }\end{array}$ & MS \\
\hline
\end{tabular}

Table 1. Biological and epidemiological data wild armadillos with pulmonary adiaspiromycosis died by motor vehicle collisions in Brazil, 2017-2020. SBA Six-Banded Armadillo, SNTA Southern Naked-Tailed Armadillo.

large numbers of epithelioid macrophages, neutrophils, lymphocytes, eosinophils, rare multinucleated giant cells (foreign body type), and fibroplasia. The granulomas could contain a viable adiaspores (up to $200 \mu \mathrm{m}$ in diameter) or cores with empty adiaspores admixed with neutrophils and necrotic cell debris. Several cases $(91.7 \%, 11 / 12)$ had hyperplasia of the lymphoid tissue associated with bronchi and bronchioles. This prompted histochemical investigation for potential Mycoplasma sp. and/or Filobacterium sp. (formerly CAR Bacillus) structures; however, these were not detected by WS stain. One armadillo had pulmonary coinfection with a trichurid nematode leading to marked bronchitis. Complete microscopic findings are listed in Table 3. No fungal structures and/or associated inflammatory response were observed in other tissues \{skin, skeletal muscle, tongue, oropharynx, tonsil, salivary glands, esophagus, stomach, small and large intestines, liver, gallbladder, pancreas, larynx, trachea, lung, heart, great vessels, thymus, spleen, lymph nodes (mandibular, prescapular, mediastinal and mesenteric), kidney, urinary bladder, thyroid and parathyroid glands, adrenal glands, diaphragm, cerebrum, cerebellum, eye, mammary gland, testicle, ovary, uterus, epididymis and prostate $\}$ examined.

Two 640-bp sequences (after excluding primers) of the fragment comprised between 18S rRNA gene and 26S rRNA gene were obtained from frozen lung samples of two six-banded armadillos (cases 10 and 12) with pulmonary intralesional adiaspores. The $26 \mathrm{~S}$ rRNA was also amplified and sequenced in these two animals. These sequences are available through the GenBank database [MT258564, MT258563, MT258566 and MT258565]. No sequences were recovered from the DNA extractions from FFPE lung samples of the remaining ten armadillos with adiaspores for any of the two selected PCR protocols.

The ITS sequences obtained from two six-banded armadillos (case 10 and 12) were identical between them, and had the highest nucleotide (NT) identity (87.6\%) to an uncultured organism amplified from the soil of the rhizosphere of tomato (Solanum lycopersicum) in Mexico (JN660517), likely E. crescens (Cordero-Ramirez et al. 2012), followed by $86.5 \%$ similarity with two E. crescens sequences from lung samples of mammals (AF038334, AF038337). The unique sequence type found in armadillos clusters separately in our ITS phylogram (Fig. 3).

The two 26S rRNA sequences obtained in this study were highly similar (97.9\% nt identity) to Emmonsiellopsis terrestris from the United States (AF038320) and Spain (KP101583), both identified from soil. The former sequence is identified in GenBank as Emmonsiella sp., but after that the same authors reclassified the sequence as Emmonsiellopsis terrestris (Marin-Felix et al. 2015). High similarity (97.6\%) was also observed to strains of Paracoccidioides brasiliensis (U93304.1, AF038360.1), and to Emergomyces europaeus (EF592164.1), E'. pasteurianus (EF592152) and different B. parvus sequences (identified in GenBank as E. parva, e.g., AF038331.1, AF038329.1, AF038328.1) with $97.4 \%$ identity (Fig. 3).

\section{Discussion}

Armadillos are among the most common species recorded in Brazilian roadkill monitoring programs, in this study were registered a total of 2941 armadillo carcasses over a 3-year period. This is primarily because some species in this group are generalist with large distribution areas and relatively high densities ${ }^{26-28}$. Examination of roadkill wildlife is pivotal for a better understanding and monitoring of infectious diseases with zoonotic potential, particularly in synanthropic and peri-urban wild animals ${ }^{1,29}$. In this study, armadillos killed by MVC were regarded as an important source of information for the surveillance of PA. 


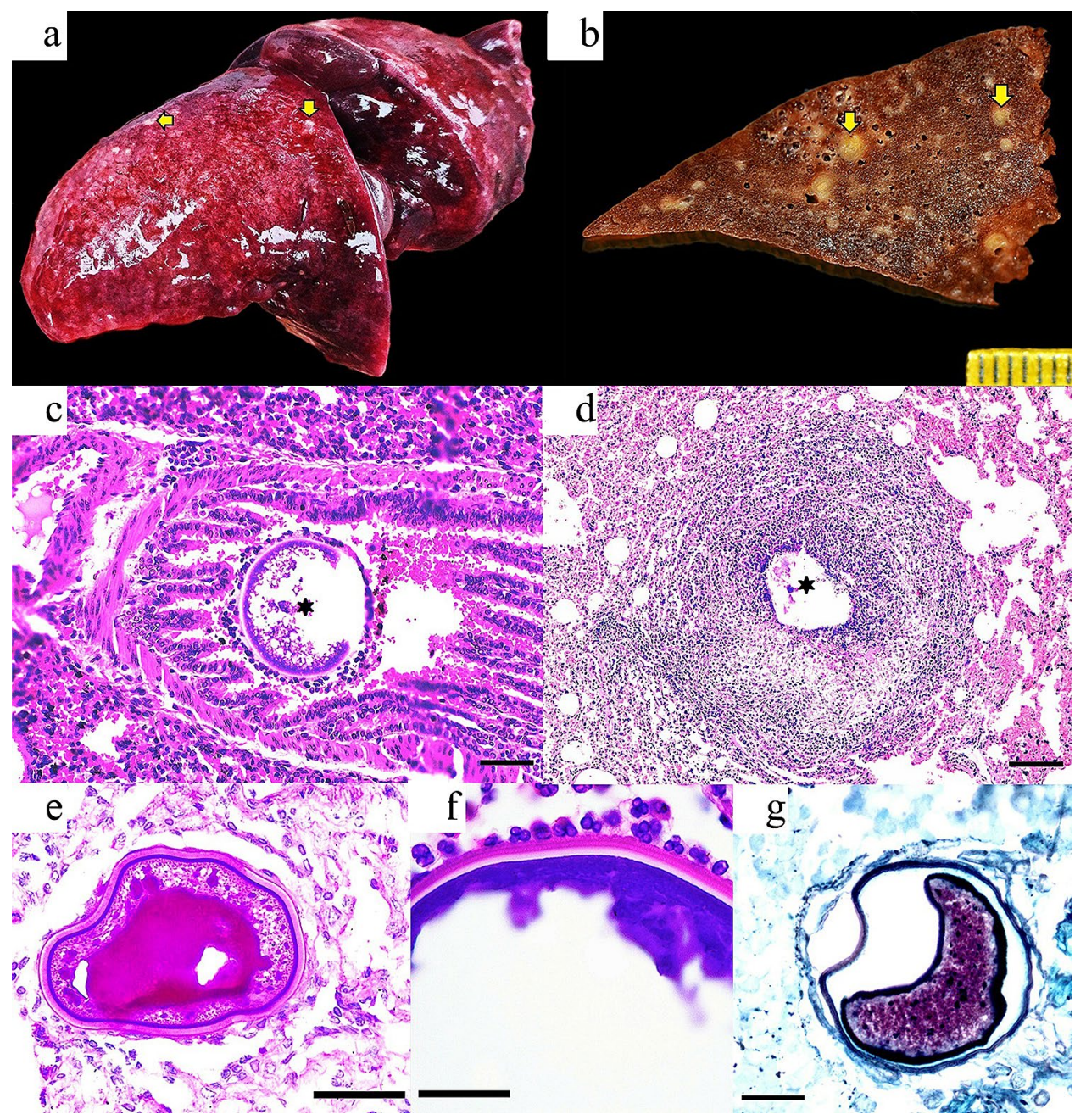

Figure 2. (a) Case 10; adult, female E. sexcinctus. The left lung lobes have heterogeneous red coloration as well as multifocal, pale tan to white subpleural nodules (yellow arrows). (b) Case 1; adult E. sexcinctus. The pulmonary parenchyma has multifocal subpleural and intraparenchymal nodules (yellow arrows) variably associated with bronchi or bronchioles. (c) Case 4; adult, male Cabassous unicinctus. Lungs. Note one adiaspores (asterisk) in the bronchial lumen surrounded by inflammatory cells. H\&E; bar $=100 \mu \mathrm{m}$. (d) Case 10; Adult, female E. sexcinctus. Note a granuloma with fragments of the adiaspores wall (asterisk) in the necrotic center. $\mathrm{H} \& \mathrm{E}$; bar $=200 \mu \mathrm{m}$. (e) Case 1; adult E. sexcinctus. Note the trilaminar wall of the adiaspores surrounded by few leukocytes. PAS; bar $=50 \mu \mathrm{m}$. (f) Case 1; adult E. sexcinctus. Detail of primarily neutrophils targeting the adiaspores wall. H\&E; bar $=25 \mu \mathrm{m}$. (g) Case 1; adult E. sexcinctus. GMS stain highlights the adiaspores wall. Bar $=25 \mu \mathrm{m}$.

Adiaspiromycosis and emmonsiosis-like fungi are isolated from the soil ${ }^{7}$. Previous studies detailed that this order (Cingulata) presents a higher occurrence of infection by Emmonsia adiaspores when compared to other mammals (marsupials, rodents, lagomorphs and carnivores) ${ }^{13}$. It is reasonable to believe that the fossorial and digging habits of armadillos likely promote inhalation of soil adiaspores and subsequent lung lesions. However, we only found cases in two of the four species collected. However, the habits of D. novemcintus are less fossorial than E. sexcinctus and C. unicinctus is actually considered subterranean ${ }^{30}$. The low sample size of $P$. maximus $(\mathrm{N}=2)$ may be why no cases were detected.

Microscopically, PA in man and animals is characterized by granulomatous pneumonia with intralesional adiaspores. The local inflammatory response includes histiocytes, neutrophils, epithelioid macrophages, lymphocytes, and occasionally multinucleated giant cells; and this is directly proportional to the adiaspores size. Adiaspores are usually bi- to trilaminar and their wall stains positive by PAS and GMS. E. crescens has a larger diameter $(200-700 \mu \mathrm{m})$ compared to $B$. parvus $(20-40 \mu \mathrm{m})^{13,16,31}$. These characteristics were observed in the armadillos analyzed in this study, however, even though the diameter of the adiaspores averaged $129.2 \mu \mathrm{m}$ $(\operatorname{Min}=10.9 \mu \mathrm{m} ; \operatorname{Max}=839.5 \mu \mathrm{m})$, being compatible with E. crescens, only $86.5 \% \mathrm{nt}$ similarity for ITS region was obtained. The culture of these fungi was not performed due to their difficulty and the need of high biosecurity levels, fact that limited technically the morphologic characterization of the fungi ${ }^{31}$. 


\begin{tabular}{|l|l|l|l|l|l|l|}
\hline Case & $\begin{array}{l}\text { Number of } \\
\text { adiaspores }\end{array}$ & $\begin{array}{l}\text { Histologic } \\
\text { distribution }\end{array}$ & Diameter (microns) & Min (microns) & Max (microns) & $\begin{array}{l}\text { Inflammatory } \\
\text { response }\end{array}$ \\
\hline 1 & 47 & $\begin{array}{l}\text { Alveolar, peribron- } \\
\text { chial }\end{array}$ & 41.9 & 10.9 & 177.5 & Granuloma \\
\hline 2 & 2 & Peribronchial & 66.1 & 52.3 & 79.9 & Histiocytic infiltration \\
\hline 3 & 15 & $\begin{array}{l}\text { Alveolar, peribron- } \\
\text { chial }\end{array}$ & 114.4 & 50.6 & 507.5 & Histiocytic infiltration \\
\hline 4 & 3 & $\begin{array}{l}\text { Peribronchial, intra- } \\
\text { bronchial }\end{array}$ & 292.4 & 257.7 & 319.8 & Granuloma \\
\hline 5 & 10 & $\begin{array}{l}\text { Alveolar, peribron- } \\
\text { chial }\end{array}$ & 39.0 & 16.9 & 81.5 & Granuloma \\
\hline 6 & 1 & Alveolar & 277.9 & 277.9 & 277.9 & Histiocytic infiltration \\
\hline 7 & 6 & $\begin{array}{l}\text { Alveolar, peribron- } \\
\text { chial }\end{array}$ & 36.6 & 29.5 & 41.3 & Histiocytic infiltration \\
\hline 8 & 1 & Peribronchial & 53.3 & 53.3 & 53.3 & Histiocytic infiltration \\
\hline 9 & 4 & $\begin{array}{l}\text { Alveolar, peribron- } \\
\text { chial }\end{array}$ & 79.5 & 69.4 & 94.7 & Histiocytic infiltration \\
\hline 10 & 13 & $\begin{array}{l}\text { Alveolar, peribron- } \\
\text { chial }\end{array}$ & 187.8 & 67.3 & 839.5 & Granuloma \\
\hline 11 & 4 & Peribronchial & 95.6 & 34.8 & 220.9 & Granuloma \\
\hline 12 & 5 & $\begin{array}{l}\text { Alveolar, intrabron- } \\
\text { chial }\end{array}$ & 266.0 & 65.8 & 485.8 & Granuloma \\
\hline
\end{tabular}

Table 2. Morphological characteristics of the adiaspores observed in lungs of wild armadillos died by motor vehicle collisions in Brazil, 2017-2020.

The identities of our ITS sequences with the nearest ones is even lower than those reported for core genes of E. parva isolates (88.6\%), a species proposed as polyphyletic, and that those proposed for E. crescens strains $(91.8 \%)$ based on genome identity ${ }^{32}$. The D1-D2 sequences are highly similar to other Onygenales species. Based on the molecular results, we identified a hitherto undescribed Onygenales species in pulmonary lesions of two six-banded armadillos causing adiaspiromycosis. Interestingly, aside from E. crescens and B. parvus, potential novel fungal species have been described in wild mammals with adiaspiromycosis, including the report of a unique sequence type more related to Emmonsiellopsis in two northern hairy-nosed wombats (Lasiorhinus krefftii) a fossorial species from Australia ${ }^{13}$. The zoonotic potential of the fungus infecting armadillos is unknown. Our molecular results raised the question about which adiaspore-producing species are infecting humans in Brazil, in light of most of the human cases are diagnosed only based on morphology, without ancillary molecular testing. To this date, in a literature review, at least 13 reports of human PA are available in the country ("Supplementary Material"). Furthermore, superficial adiaspiromycosis was reported to cause granulomatous conjunctivitis in children in the Amazon basin, and histopathologic examination of ocular nodules identified adiaspores-like structures ${ }^{10}$. Future studies molecularly identifying the fungal species in humans are necessary to explore the epidemiology of the disease, including the use of armadillo species as indicator of potential exposure areas to humans.

In summary, we provide pathological and molecular evidence of a relatively poorly known fungal disease in wild armadillos. Both, the morphology of the fungus, as well as the histopathological findings (granulomatous inflammatory response to adiaspores) are consistent with PA; however, as molecular identification differs from the reported species, the potential impact of this fungus for human PA is unknown, and we cannot rule out its impact on public health. To the authors' knowledge this is the largest report of this disease in wild mammals from Brazil.

\section{Methods}

Road monitoring. Between February 2017 and February 2020, a periodic road monitoring was carried out to identify the number of armadillos killed by MVC in two states of Brazil, Mato Grosso do Sul (MS) and Sao Paulo (SP) (See 25 for details) ${ }^{25}$. Epidemiological and biological data [species, age class, sex, season (rainy or dry) and coordinates] were recorded from all carcasses. Roadkilled armadillos in good preservation status were selected for investigate the occurrence and pathological features of adiaspiromycosis by anatomopathological study $^{33}$.

Pulmonary adiaspiromycosis survey. Representative tissue samples of lungs, trachea and tracheobronchial lymph nodes were collected, and fixed in $10 \%$ neutral buffered formalin or frozen at $-20{ }^{\circ} \mathrm{C}$ or $-80{ }^{\circ} \mathrm{C}$. These tissues were processed routinely, embedded on paraffin-wax, sectioned at $5 \mu \mathrm{m}$-thick and stained with hematoxylin and eosin (H\&E) for routine microscopic analysis. Special stains periodic acid-Schiff (PAS), Grocott methenamine silver (GMS), Masson's trichrome (MS) and Warthin-Starry stain (WS) were applied in selected cases to better characterize the histopathologic findings. Microphotographs of the adiaspores were collected and subsequently measured using the Image J software ${ }^{34}$. 


\begin{tabular}{|c|c|}
\hline Microscopic finding & Total \\
\hline \multicolumn{2}{|l|}{ Vascular/hemodynamic } \\
\hline Congestion & $100 \%(12 / 12)$ \\
\hline Hemorrhage & $100 \%(12 / 12)$ \\
\hline Edema & $83.3 \%(10 / 12)$ \\
\hline Endothelial hypertrophy & $75 \%(9 / 12)$ \\
\hline Hemosiderosis & $58.3 \%(7 / 12)$ \\
\hline Tunica media hypertrophy/hyperplasia & $50 \%(6 / 12)$ \\
\hline Vasculitis/perivasculitis & $50 \%(6 / 12)$ \\
\hline \multicolumn{2}{|c|}{ Alveoli, bronchial/bronchiolar submucosa, interstitium, pleura } \\
\hline Macrophagic infiltration $^{\mathrm{a}}$ & $100 \%(12 / 12)$ \\
\hline Presence of adiaspores ${ }^{\mathrm{a}}$ & $100 \%(12 / 12)$ \\
\hline Lymphocytic infiltration & $91.7 \%(11 / 12)$ \\
\hline BALT hyperplasia & $91.7 \%(11 / 12)$ \\
\hline Hemorrhage & $83.3 \%(10 / 12)$ \\
\hline Atelectasia & $83.3 \%(10 / 12)$ \\
\hline Plasma cell infiltration & $66.7 \%(8 / 12)$ \\
\hline Bronchoconstriction & $58.3 \%(7 / 12)$ \\
\hline Granuloma & $50 \%(6 / 12)$ \\
\hline Anthracosis & $50 \%(6 / 12)$ \\
\hline Neutrophilic infiltration $^{\mathrm{a}}$ & $41.7 \%(5 / 12)$ \\
\hline Eosinophilic infiltration & $41.7 \%(5 / 12)$ \\
\hline Hemosiderophages & $41.7 \%(5 / 12)$ \\
\hline Multinucleated giant cells & $33.3 \%(4 / 12)$ \\
\hline Nematode eggs (Capillaria sp.) & $25 \%(3 / 12)$ \\
\hline Mucus & $25 \%(3 / 12)$ \\
\hline Fibrin & $16.7 \%(2 / 12)$ \\
\hline Fibrosis & $16.7 \%(2 / 12)$ \\
\hline Necrotic cell debris & $8.3 \%(1 / 12)$ \\
\hline Aspirated particles & $8.3 \%(1 / 12)$ \\
\hline \multicolumn{2}{|l|}{ Mucosa/epithelium } \\
\hline Sloughing/loss & $100 \%(12 / 12)$ \\
\hline Erosion & $100 \%(12 / 12)$ \\
\hline Hyperplasia of goblet cells & $50 \%(6 / 12)$ \\
\hline Bone marrow metaplasia & $41.7 \%(5 / 12)$ \\
\hline Multinucleated giant cells & $33.3 \%(4 / 12)$ \\
\hline Necrosis & $25 \%(3 / 12)$ \\
\hline Type II pneumocyte hyperplasia & $25 \%(3 / 12)$ \\
\hline Calcification & $8.3 \%(1 / 12)$ \\
\hline
\end{tabular}

Table 3. Microscopic pulmonary findings in armadillos with pulmonary adiaspiromycosis died by motor

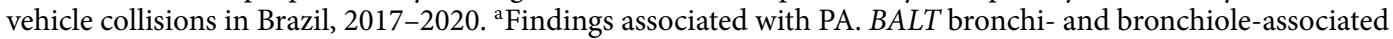
lymphoid tissue.

Molecular analysis. When adiaspores and/or associated lesions were found in the histopathological evaluation, total DNA was extracted from available frozen lung samples $(n=2)$ using the ZR Fungal/Bacterial DNA Miniprep kit (Zymo, Irvine, CA, USA), according to the manufacturer's instructions. In cases, without available frozen sample $(n=10)$, DNA extraction of formalin-fixed and paraffin-embedded (FFPE) tissue was performed according to standardized protocols ${ }^{35}$. A panfungal PCR using the primers ITS1-F and ITS- 4 at a melting temperature of $55^{\circ} \mathrm{C}$ was performed to amplify a 700-bp fragment comprising the $18 \mathrm{~S}$ rRNA gene, internal transcribed spacer-1 (ITS-1), 5.8S rRNA gene and ITS-2, until the $26 \mathrm{~S}$ rRNA gene ${ }^{36}$. The variable regions D1 and D2 of the $26 \mathrm{~S}$ rRNA gene of fungi were amplified by PCR using primers NL1 and NL4 ${ }^{37}$. Amplicons of the expected size were purified with Exo-Sap IT (GE Healthcare, Waukesha, WI, USA) or Illustra DNA and Gel Band Purification kit (GE Healthcare, UK, if two bands were present in the agarose gel) and confirmed by direct Sanger sequencing. After a ClustalW alignment in Mega $7.0^{38}$, the obtained sequences (excluding primers) were compared with those available in GenBank using Blast search (http://www.ncbi.nlm.nih.gov/blast). The percentage of nucleotide (nt) identity of the obtained sequences to the closest available on GenBank was calculated based on p-distance $([1-\mathrm{p}$-distance $] \times 100)$. A 1000 bootstrap maximum likelihood phylogram was constructed with the obtained ITS sequences, those from selected Onygenales species retrieved from GenBank and Aspergillus terreus as outgroup (MH141230). 


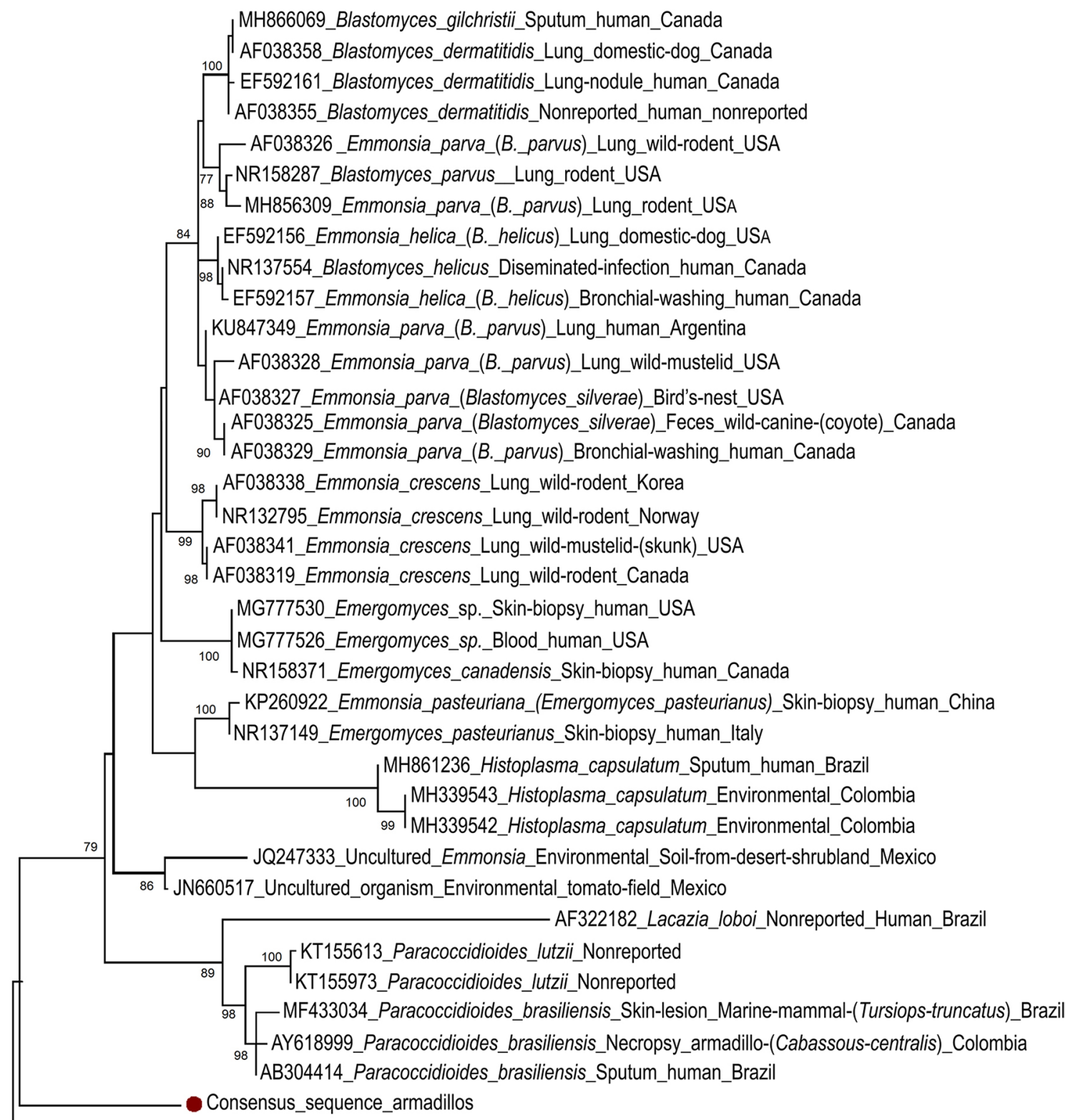

MH141230.1_Aspergillus terreus

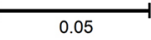

Figure 3. Maximum likelihood phylogram with 1000 bootstrap replicates of the alignment of the consensus internal transcriber spacer (ITS) 1, 5.8S rRNA gene and ITS 2 nucleotide sequence obtained in two six-banded armadillos (Euphractus sexcinctus) from this study, 35 selected fungi of the order Onygenales and Aspergillus terreus (MH141230) as outgroup.

Ethical standards. This study was carried out in compliance with the System Authorization and Information on Biodiversity (SISBIO) of the Brazilian Institute of Environment and Renewable Natural Resources (IBAMA) (license number: 58745) and was approved by the Ethics Committee on Animal Use (CEUA) of the School of Veterinary Medicine and Animal Science-University of São Paulo (FMVZ-USP) (protocol number: 7198020317). All animals were dead at the time of necropsy; no animals were euthanized in this study.

\section{Data availability}

All data generated or analyzed during this study are included in this published article.

Received: 19 May 2020; Accepted: 4 December 2020

Published online: 11 January 2021 


\section{References}

1. Morner, T., Obendorf, D. L., Artois, M. \& Woodford, M. H. Surveillance and monitoring of wildlife diseases. Rev. Sci. Tech. 21(1), 67-76 (2002).

2. Daszak, P., Cunningham, A. A. \& Hyatt, A. D. Emerging infectious diseases of wildlife-threats to biodiversity and human health. Science 287(5452), 443-449 (2000).

3. Bagagli, E. et al. Isolation of Paracoccidioides brasiliensis from armadillos (Dasypus noveminctus) captured in an endemic area of paracoccidioidomycosis. Am. J. Trop. Med. Hyg. 58(4), 505-512 (1998).

4. Truman, R. Leprosy in wild armadillos. Leprosy Rev. 76(3), 198-208 (2005).

5. da Silva, M. B. et al. Evidence of zoonotic leprosy in Pará, Brazilian Amazon, and risks associated with human contact or consumption of armadillos. PLOS Neglect. Trop. D. 12(6), e0006532. https://doi.org/10.1371/journal.pntd.0006532 (2018).

6. Rodrigues, T. F., Mantellatto, A. M., Superina, M. \& Chiarello, A. G. Ecosystem services provided by armadillos. Biol. Rev. 95(1), $1-21(2020)$.

7. Jiang, Y. et al. Phylogeny, ecology and taxonomy of systemic pathogens and their relatives in Ajellomycetaceae (Onygenales): Blastomyces, Emergomyces, Emmonsia, Emmonsiellopsis. Fungal Divers. 90(1), 245-291 (2018).

8. Schwartz, I. S. et al. 50 years of Emmonsia disease in humans: The dramatic emergence of a cluster of novel fungal pathogens. PLoS Pathog. 11(11), e1005198. https://doi.org/10.1371/journal.ppat.1005198 (2015).

9. Moraes, M. A., Gomes, M. I. \& Vianna, L. M. S. Pulmonary adiaspiromycosis: Casual finding in a deceased yellow fever patient [in Portuguese]. Rev. Soc. Bras. Med. Trop. 34(1), 83-85 (2001).

10. Mendes, M. O. et al. Acute conjunctivitis with episcleritis and anterior uveitis linked to adiaspiromycosis and freshwater sponges, Amazon region, Brazil, 2005. Emerg. Infect. Dis. 15(4), 633 (2009).

11. Emmons, C. W. \& Ashburn, L. L. The isolation of Haplosporangium parvum n. sp. and Coccidioides immitis from wild rodents. Their relationship to coccidioidomycosis. Public Health Rep. 57(46), 1715-1727 (1942).

12. Doby-Dubois, M., Chevrel, M. L., Doby, J. M. \& Louvet, M. First human case of adiaspiromycosis by Emmonsia crescens, Emmons and Jellison 1960 [in french]. Bull. Soc. Pathol. Exot. 57, 240-244 (1964).

13. Danesi, P. et al. Molecular diagnosis of Emmonsia-like fungi occurring in wild animals. Mycopathologia 185, 51-65 (2020).

14. Peres, L. C., Figueiredo, F., Peinado, M. \& Soares, F. A. Fulminant disseminated pulmonary adiaspiromycosis in humans. Am. J. Trop. Med. Hyg. 46(2), 146-1450 (1992).

15. Mörner, T., Avenäs, A. \& Mattsson, R. Adiaspiromycosis in a European beaver from Sweden. J. Wildl. Dis. 35(2), 367-370 (1999).

16. Simpson, V. R. \& Gavier-Widen, D. Fatal adiaspiromycosis in a wild Eurasian otter (Lutra lutra). Vet. Rec. 147(9), 239-241 (2000).

17. Pusterla, N. et al. Disseminated pulmonary adiaspiromycosis caused by Emmonsia crescens in a horse. Equine Vet. J. 34(7), 749-752 (2002).

18. Kenyon, C. et al. A dimorphic fungus causing disseminated infection in South Africa. N. Engl. J. Med. 369(15), 1416-1424 (2013).

19. Santos, V. M. D., Fatureto, M. C., Saldanha, J. C. \& Adad, S. J. Pulmonary adiaspiromycosis: Report of two cases. Rev. Soc. Bras. Med. Trop. 33(5), 483-488 (2000).

20. Moraes, M. A. \& Gomes, M. I. Human adiaspiromycosis: Cicatricial lesions in mediastinal lymph nodes [in Portuguese]. Rev. Soc. Bras. Med. Trop. 37(2), 177-178 (2004).

21. Pfaller, M. A. \& Diekema, D. J. Unusual fungal and pseudofungal infections of humans. J. Clin. Microbiol. 43(4), 1495-14504 (2005).

22. Ministério da Saúde do Brasil. Ed. 3. Risk Classification of Biological Agents [in Portuguese]. Brasil. Ministério da Saúde. Secretaria de Ciência, Tecnologia e Insumos Estratégicos. Departamento do Complexo Industrial e Inovação em Saúde, 48 (2017). ISBN 978-85-334-2547-7.

23. Richini-Pereira, V. B., Bosco, S. M. G., Theodoro, R. C., Barrozo, L. \& Bagagli, E. Road-killed wild animals: A preservation problem useful for eco-epidemiological studies of pathogens. J. Venom. Anim. Toxins Incl. Trop. Dis. 16(4), 607-613 (2010).

24. Jellison, W. L. \& Lord, R. D. Adiaspiromycosis in Argentine mammals. Mycologia 56(3), 374-383 (1964).

25. Ascensão, F., Yogui, D., Alves, M., Medici, E. P. \& Desbiez, A. Predicting spatiotemporal patterns of road mortality for mediumlarge mammals. J. Environ. 248, 109320. https://doi.org/10.1016/j.jenvman.2019.109320 (2019).

26. Cáceres, N. C. Biological characteristics influence mammal roadkill in an Atlantic Forest-Cerrado interface in south-western Brazil. Ital. J. Zool. 78(3), 379-389 (2011).

27. Ascensão, F., Desbiez, A. L., Medici, E. P. \& Bager, A. Spatial patterns of road mortality of medium-large mammals in Mato Grosso do Sul, Brazil. Wildlife Res. 44(2), 135-1346 (2017).

28. Ribeiro, P., Miranda, J. S. \& de Araújo, D. R. The effect of roadkills on the persistence of xenarthran populations: the case of the Brazilian Cerrado. Edentata 18, 51-61 (2017).

29. Zhu, X., Xu, J. M., Marsh, C. M., Hines, M. K. \& Dein, F. J. Machine learning for zoonotic emerging disease detection. In International Conference on Machine Learning. Proc. 2011 Workshop on Machine Learning for Global Challenges, Bellevue, WA, USA. http://pages.cs.wisc.edu/ jerryzhu/pub/WHER.pdf (2011).

30. Desbiez, A. L. J., Massocato, G. F., Kluyber, D. \& Santos, R. C. F. Unraveling the cryptic life of the southern naked-tailed armadillo, Cabassous unicinctus squamicaudis (Lund, 1845), in a Neotropical wetland: home range, activity pattern, burrow use and reproductive behaviour. Mamm. Biol. 91(1), 95-103 (2018).

31. Borman, A. M., Simpson, V. R., Palmer, M. D., Linton, C. J. \& Johnson, E. M. Adiaspiromycosis due to Emmonsia crescens is widespread in native British mammals. Mycopathologia 168(4), 153-163 (2009).

32. Muñoz, J. F., McEwen, J. G., Clay, O. K. \& Cuomo, C. A. Genome analysis reveals evolutionary mechanisms of adaptation in systemic dimorphic fungi. Sci. Rep. 8(1), 1-13 (2018).

33. Munson, L. et al. Necropsy of Wild Animals (Wildlife Health Center, School of Veterinary Medicine, University of California Davis, Davis, 2006).

34. Abràmoff, M. D., Magalhães, P. J. \& Ram, S. J. Image processing with ImageJ. Biophotonics Intern. 11(7), 36-42 (2004).

35. Sambrook, J., Fitsch, E. F. \& Maniatis, T. Molecular cloning. In A Laboratory Manual (eds Sambrook, J. et al.) 65-69 (Cold Spring Harbor, New York, 1989).

36. Sacristán, C., Esperón, F., Ewbank, A.C., Kolesnikovas, C.K.M., Catão-Dias, J.L. Paracoccidioidomycosis ceti in an Atlantic bottlenose dolphin (Tursiops truncatus), Brazil. Transbound. Emerg. Dis. 65(2):585-87 (2018).

37. Coutinho, S. D. A. et al. Malassezia japonica is part of the cutaneous microbiome of free-ranging golden-headed lion tamarins (Leontopithecus chrysomelas-Kuhl, 1820). Med. Mycol. J. 58(1), 133-136 (2020).

38. Kumar, S. et al. Molecular diversity of terpene synthases in the liverwort Marchantia polymorpha. Plant Cell. 28(10), 2632-2650 (2016).

\section{Acknowledgements}

Special thanks to the staff and volunteers of the Anteater \& Highways Project which is funded by Foundation Segre and other partners listed at www.giantanteater.org/supporters; technical and administrative staff of the Tamoios, Prime and Arteris toll roads; technicians and collaborators of the animal pathology department of the School of Veterinary Medicine and Animal Science of University of Sao Paulo (VPT/FMVZ/USP). To the 
members of the museum of Veterinary Anatomy (MAV/FMVZ/USP). Sacristán C is a recipient of a post-doctoral fellowship from the Sao Paulo Research Foundation (FAPESP; Grant \#2018/25069-7). Díaz-Delgado J is a recipient of a post-doctoral fellowship from FAPESP (Grant \#2017/02223-8). Catão-Dias JL is the recipient of a fellowship from the National Research Council (CNPq; Grant \# 304999-18). This research was also supported by Coordination for the Improvement of Higher Education Personnel (CAPES).

\section{Author contributions}

Perform experiments P.E.N.S., D.R.Y. and M.H.A. Analyze experiments P.E.N.S., C.S., J.D.D., D.F.C., C.O.P., and R.R.Z. Design the study P.E.N.S., J.D.D., A.L.J.D. and J.L.C.D Wrote the paper P.E.N.S. with the contribution of all coauthors. Supervise the study J.L.C.D., and J.D.D.

\section{Competing interests}

The authors declare no competing interests.

\section{Additional information}

Supplementary Information The online version contains supplementary material available at https://doi.org/ 10.1038/s41598-020-79521-6.

Correspondence and requests for materials should be addressed to P.E.N.-S.

Reprints and permissions information is available at www.nature.com/reprints.

Publisher's note Springer Nature remains neutral with regard to jurisdictional claims in published maps and institutional affiliations.

(1) Open Access This article is licensed under a Creative Commons Attribution 4.0 International License, which permits use, sharing, adaptation, distribution and reproduction in any medium or format, as long as you give appropriate credit to the original author(s) and the source, provide a link to the Creative Commons licence, and indicate if changes were made. The images or other third party material in this article are included in the article's Creative Commons licence, unless indicated otherwise in a credit line to the material. If material is not included in the article's Creative Commons licence and your intended use is not permitted by statutory regulation or exceeds the permitted use, you will need to obtain permission directly from the copyright holder. To view a copy of this licence, visit http://creativecommons.org/licenses/by/4.0/.

(C) The Author(s) 2021, corrected publication 2021 